\title{
Bone marrow Schwann cells induce hematopoietic stem cell hibernation
}

\author{
Satoshi Yamazaki • Hiromitsu Nakauchi
}

Received: 4 April 2014/ Accepted: 25 April 2014/Published online: 10 May 2014

(C) The Japanese Society of Hematology 2014

\begin{abstract}
Hematopoietic stem cells (HSCs) are clonogenic cells capable of both self-renewal and multilineage differentiation. In adult mouse bone marrow (BM), most HSCs remain in the non-dividing $\mathrm{G}_{0}$-phase of cell cycle, in close contact with supporting cells known as the HSC "niche". In the present study, we focused on signaling mechanisms that regulate stem cell dormancy in the BM niche. We show that TGF- $\beta$ type II receptor deficiency causes reduced phosphorylation of Smad $2 / 3$ and impairs long-term repopulating activity in HSCs, suggesting a significant role for TGF- $\beta / S$ mad signaling in hematopoiesis. Furthermore, we aimed at defining the candidate BM niche responsible for homeostasis of hematopoiesis, and revealed that non-myelinating Schwann cells sustain HSC hibernation by converting TGF- $\beta$ from its latent to its active form.
\end{abstract}

Keywords Hematopoietic stem cell - Hibernation · TGF- $\beta$ signaling $\cdot$ Schwann cell

\section{Introduction}

Hematopoietic stem cells (HSCs) reside in the bone marrow (BM) niche while remaining in a state of quiescence, and are recruited into the cell cycle at long intervals [1-4]. This unique property of HSCs is in some ways reminiscent

S. Yamazaki $(\bowtie) \cdot$ H. Nakauchi

Laboratory of Stem Cell Therapy, Center for Experimental

Medicine, The Institute of Medical Science, University of

Tokyo, Tokyo 108-8639, Japan

e-mail: y-sato4@ims.u-tokyo.ac.jp

H. Nakauchi

e-mail: nakauchi@ims.u-tokyo.ac.jp of hibernation in mammals $[5,6]$. Although a number of cytological studies have attempted to characterize a candidate niche, there have been few reports of the inter- and intra-cellular signaling mechanisms that underlie HSC 'hibernation'. This is largely due to the paucity of HSCs, which makes the use of traditional signal transduction assays difficult [7]. To address these issues, we developed a novel assay based on in-droplet single-cell staining and quantitative fluorescence imaging analysis [7, 8]. Using this assay system, we demonstrated that HSCs freshly isolated from the BM lack lipid raft clustering, exhibit repression of the AKT-FOXO signaling pathway [9, 10], and express abundant p57Kip2 cyclin-dependent kinase inhibitor [11, 12]. Subsequent studies also demonstrated that lipid raft clustering induced by cytokines is essential for HSC cell cycle re-entry [13].

Inhibition of lipid raft clustering in contrast caused sustained nuclear accumulation of FOXO transcription factors (FOXO1, FOXO3, FOXO4, and FOXO6) and induced HSC hibernation ex vivo. Among niche signals examined, transforming growth factor-beta (TGF- $\beta$ ) efficiently inhibited lipid raft clustering and induced p57Kip2 expression, leading to HSC hibernation [14]. These data reveal a critical role for lipid rafts in HSC fate determination, and establish the importance of TGF- $\beta$ in the control of HSC hibernation in the BM niche. Moreover, we demonstrated that TGF- $\beta$ type II receptor-deficient HSCs show low-level Smad activation and impaired long-term repopulating activity, suggesting a critical role for TGF- $\beta$ / Smad signaling in HSC maintenance $[15,16]$. Considering that TGF- $\beta$ is produced in a latent form by a variety of cells, we searched for effector cells in BM-expressing signal molecules that activate latent TGF- $\beta$. In the present report, we describe how we identified Schwann cells in BM as important for the maintenance of HSC hibernation [17]. 


\section{Impaired HSC function in Tgfbr2-deficient mice; Smad2/3 are highly activated in HSCs}

To establish the role of TGF- $\beta$ in the control of HSC hibernation, we generated conventional Tgfbr2 knockout mice [18]. As expected from the significant role of TGF- $\beta$ in cell growth, inflammation and apoptosis, the mice developed a lethal inflammatory disease (LID) [19]. Similarly, transplantation of the immune cells from $T g f b r 2$ knockout mice developed the same disease phenotypes due to an uncontrolled over-reaction of lymphocytes [20]. We therefore generated conditional Tgfbr2-deficient ( $M x-1$ Cre: $\left.T g f b r 2^{f l o x /-} ; R_{a g 2^{-/-}}\right)$mice, which do not develop LID due to a lack of $\mathrm{T}$ and $\mathrm{B}$ cells. We then injected polyinosinic-polycytidylic acid (pIpC) intraperitoneally three times every other day to induce $\mathrm{Cre}$ recombinase activity [21]. Two weeks after pIpC injection, total BM cells were infused into lethally irradiated recipients along with the competitor BM cells. In the current study, peripheral blood (PB) myeloid chimerism was used as the indicator of the repopulation ability of test cells. As a result, chimerism of $T g f b r 2$-deficient BM cells over wild type gradually decreased. These results led us to hypothesize that $T g f b r 2$-deficient HSCs exhibit impaired longterm repopulating activity. To address this possibility, we examined the process of cell cycle or the phosphorylation status of Smad2/3, downstream targets of TGF- $\beta$ signaling. Our results clearly indicate that the levels of phosphorylated Smad2/3 in $T g f b r 2^{\text {dell- }}$ Rag $^{-1-}$ CD $34^{-}$KSL HSCs 2 weeks after $\mathrm{pIpC}$ injection are significantly lower than those in wild-type $\left(\mathrm{Tg}_{\mathrm{fbr}}{ }^{+/+} \mathrm{Rag} 2^{-/-} \mathrm{CD} 34^{-} \mathrm{KSL}\right) \mathrm{HSCs}$. $\mathrm{BrdU}$ incorporation assay also revealed that a significantly higher proportion of $\mathrm{Tg} f b r 2^{\mathrm{del} /}-\mathrm{Rag} 2^{-/-} \mathrm{CD} 34^{-} \mathrm{KSL}$ HSCs entered the cell cycle within a week compared with $\mathrm{Tg}_{\mathrm{fbr}}{ }^{+/+} \mathrm{Rag}^{-/-} \mathrm{CD} 34^{-} \mathrm{KSL}$ HSCs. Taken together, these results show that loss of $T g f b r 2$ causes reduced phosphorylation of $\mathrm{Smad} 2 / 3$, increased cell cycling, and reduced long-term repopulating activity in HSCs, demonstrating that TGF- $\beta /$ Smad signaling is active in maintaining the hibernation of BM HSCs.

\section{A specialized cell type produces active TGF- $\beta$ in BM}

Although, TGF- $\beta$ is produced by various types of blood cells, including HSCs, how it is activated remains obscure. The identification and characterization of cell types that activate TGF- $\beta$ is thus crucial to the understanding of the physiological role of TGF- $\beta$ in the BM niche. To address this issue, we conducted studies aimed at defining cell type using two different antibodies: anti-LAP and anti-TGF- $\beta$. Anti-LAP antibody was used to detect latent TGF- $\beta$ while anti-TGF- $\beta$ antibody was used to detect active TGF- $\beta$. In

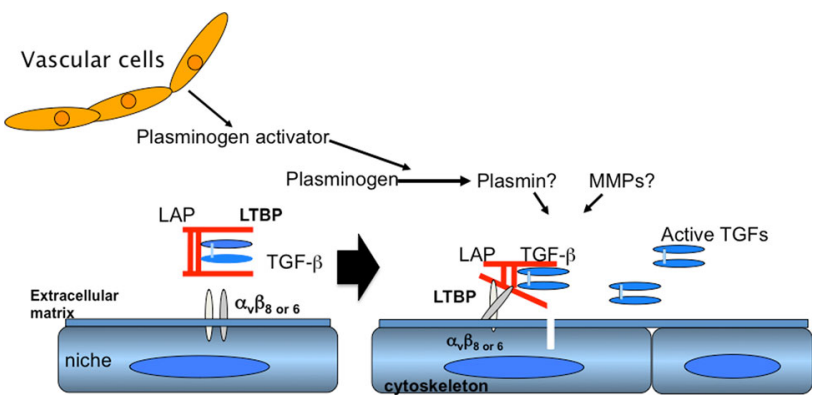

Fig. 1 Processes of Latent TGF- $\beta$ activation. TGF- $\beta$ s are secreted as latent complexes containing these forms: active TGF- $\beta$, latencyassociated protein (LAP), and latent TGF- $\beta$ binding protein (LTBP). This ternary complex is called the large latent complex (LLC). Because LTBP-1, a member of the LTBP/fibrillin family, covalently binds to extracellular matrix (ECM) proteins, LLC accumulates in the ECM. Under most conditions, TGF- $\beta$ is secreted as part of the LLC. TGF- $\beta$ function is therefore largely controlled by activation of latent TGF- $\beta$, a process that involves dissociation of bioactive TGF- $\beta$ from LAP

BM sections fixed with dry ice-cold ethanol [22], LAP was abundantly detected in various cells known to produce latent TGF- $\beta$, including megakaryocytes. However, active TGF- $\beta$ expression was highly restricted to a small population of LAP-positive cells with a long, spindle-shaped structure. Notably, integrin- $\beta 8$ (Itgb8) $[23,24]$ was more specifically expressed in the same population of LAPpositive cells. These findings indicate that anti-TGF- $\beta$ antibody recognizes a specialized cell type with a long, spindle-shaped structure producing active TGF- $\beta$ in BM (Fig. 1).

\section{GFAP-positive cells activate latent TGF- $\beta$}

We next examined to determine Itgb8-positive BM cell type responsible for active TGF- $\beta$ production. However, RT-PCR analysis showed that neither HSCs nor BM stromal cells express Itg b8. We therefore decided to focus on Schwann cells, which are known to express Itgb8. There are two types of Schwann cells, myelinating and nonmyelinating [25]. Myelinating Schwann cells express myelin basic protein (MBP), but not glial fibrillary acidic protein (GFAP), while non-myelinating Schwann cells express GFAP, but not MBP. We investigated BM sections from GFAP promoter-driven GFP transgenic mice [26] and found that most GFP-positive cells stained for active TGF$\beta$. These cells also expressed Itg $b 8$, a marker antigen for glial cells. Interestingly, these GFAP-positive cells were present in parallel with neurofilament (NF)-positive axons. Analysis of transverse sections together with immunostaining revealed that GFAP-positive cells are positive for active TGF- $\beta$ and Itg $b 8$, and ensheath NF- and tyrosine hydroxylase (TH)-positive axons. 
Furthermore, VE-cadherin positive endothelial cells and GFAP- and Itgb8-positive cells were found to be discrete cell populations, located in parallel and in close proximity to each other. These results led us to suggest that non-myelinating Schwann cells in BM are responsible for HSC hibernation.

\section{HSCs exist in contact with GFAP-positive cells in BM}

To ask whether HSCs stay in close contact with BM Schwann cells, we performed ArrayScan analysis of BM sections to determine the positional relationship between HSCs and BM GFAP-positive cells. GFAP-expressing Schwann cells were in direct contact with about $20 \%$ of $\mathrm{CD} 150^{+} \mathrm{CD} 48^{-} \mathrm{CD} 41^{-} \mathrm{Lin}^{-}$ HSCs [27], whereas 13 and $30 \%$ of HSCs were in contact with osteoblastic cells and vascular cells, respectively. However, $32 \%$ of HSCs stayed apart from any of these cells, perhaps in contact with unidentified cells or may be due to scanning failure. Of particular interest was that Schwann cells prepared from sciatic nerves expressed major HSC niche factor genes such as $\mathrm{Cxcl12}$ [28, 29], kitl [30], Angpt1 [3], and Tpo [31] as well as TGF- $\beta$ and Itgb8. Collectively, these data suggest that BM Schwann cells are prime candidates for constituents of the BM niche.

\section{Denervation of sympathetic nerve results in loss of HSCs}

To address the functional significance of BM Schwann cells as a BM niche candidate affecting HSC hibernation, we explored to delete ensheathing GFAP-positive cells in BM via Wallerian degeneration by transecting postganglionic sympathetic nerves [32]. Nerve injury induces a reduction of neuregulin-1 signaling and eventually triggers apoptosis of Schwann cells [33]. For this purpose, the lumbar sympathetic trunk was cut unilaterally at L2, L3, and L4 to denervate sympathetic nerves to the biceps femoris muscle and BM [34]. This surgical strategy revealed a statistically significant decrease in the number of GFAP- and activation of TGF- $\beta$-positive cells when compared with sham-operated controls. The number of HSCs on the denervated side continued to decline till day 3, and eventually fell to one-fifth of those in the sham side by day 7 , whereas other niches components remained intact even after 1 week following denervation. These findings provide intriguing evidence that loss of Schwann cells after denervation surgery leads to a decrease of HSCs.

\section{Sympathetic nerve denervation compromises dormancy of HSCs}

To further confirm loss of HSCs after denervation, competitive repopulation analysis was performed using $\mathrm{BM}$

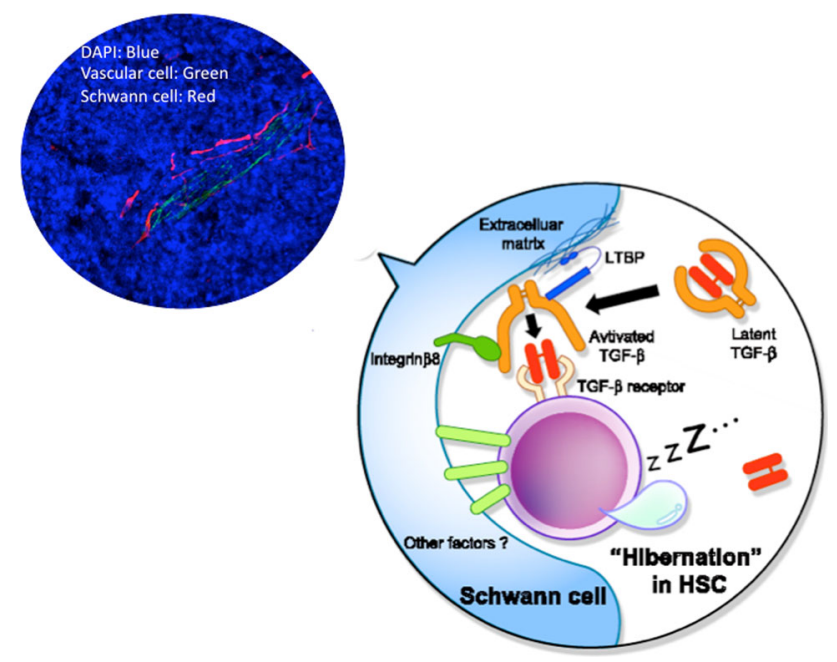

Fig. 2 BM Schwann cells maintain HSC hibernation in the niche. By regulating the activation process of TGF- $\beta$, these Schwann cells appear to control hibernation of HSCs in BM. How components of the $\mathrm{BM}$ niche are related in the maintenance of homeostasis of HSCs under the influence of the autonomic nervous system remains an intriguing issue. Identification of Schwann cells as BM HSC niche constituents opens a new area of research that links the neural and hematopoietic systems

cells harvested 1 month after sympathetic nerve transection. Three months later, we analyzed donor chimerism in PB and observed significantly lower chimerism in mice transplanted with BM cells derived from the denervated side than those from the sham-operated contralateral side. Competitive repopulation assay revealed no significant difference between $\mathrm{CD} 34^{-} \mathrm{KSL}$ cells purified from denervated $\mathrm{BM}$ and those from control BM. To explain why reconstitution activity of HSC is decreased after denervation, we examined phosphorylation levels of $\operatorname{Smad} 2 / 3$ in HSCs. The results showed profound down-regulation of $\mathrm{pSmad} 2 / 3$ in HSCs following denervation. Furthermore, cell cycle analysis revealed a significant proportion of HSCs isolated from denervated BM are positive for BrdU, indicating accelerated cell cycle progression. Notably, infusion of active TGF- $\beta$ suppressed active cycling of HSCs in denervated mice, but latent TGF- $\beta$ did not. These results support the idea that glial cells are component of BM niche and sustain HSC hibernation by converting latent TGF- $\beta$ into active form (Fig. 2).

\section{Conclusion}

In present study, we sought to define cells and signals that regulate HSC hibernation in the BM niche. The results of experiments using conditional knockout mouse models revealed the crucial cell type for HSC hibernation to be non-myelinating Schwann cells. These cells produce active 
TGF- $\beta$, which phosphorylates Smad2/3, leading to cell cycle progression. We propose that these cells are components of BM niche and sustain hibernating HSCs by converting latent TGF- $\beta$ into its active form.

Acknowledgments We would like to thank Dr. Masataka Kasai for discussion and critical reading of manuscript.

Conflict of interest The authors declare no conflicts of interest.

\section{References}

1. Sudo K, Ema H, Morita Y, Nakauchi H. Age-associated characteristics of murine hematopoietic stem cells. J Exp Med. 2000;192:1273-80.

2. Foudi A, Hochedlinger K, Van Buren D, Schindler JW, et al. Analysis of histone 2B-GFP retention reveals slowly cycling hematopoietic stem cells. Nat Biotechnol. 2009;27:84-90.

3. Arai F, Hirao A, Ohmura M, et al. Tie2/angiopoietin-1 signaling regulates hematopoietic stem cell quiescence in the bone marrow niche. Cell. 2004;118:149-61.

4. Morrison SJ, Scadden DT. The bone marrow niche for haematopoietic stem cells. Nature. 2014;16:327-34.

5. Cai D, McCarron RM, Hallenbeck J. Cloning and characterization of a forkhead transcription factor gene, FOXO1a, from thirteen-lined ground squirrel. Gene. 2004;343:203-9.

6. Cai D, McCarron RM, Yu EZ, Li Y, et al. Akt phosphorylation and kinase activity are down-regulated during hibernation in the 13-lined ground squirrel. Brain Res. 2004;1014:14-21.

7. Ema H, Morita Y, Yamazaki S, et al. Adult mouse hematopoietic stem cells: purification and single-cell assays. Nat Protoc. 2006;1:2979-87.

8. Seita J, Ema H, Ooehara J, Yamazaki S, et al. Lnk negatively regulates self-renewal of hematopoietic stem cells by modifying thrombopoietin-mediated signal transduction. Proc Natl Acad Sci USA. 2007;13:2349-54.

9. Tothova Z, Kollipara R, Huntly BJ, Lee BH, et al. FoxOs are critical mediators of hematopoietic stem cell resistance to physiologic oxidative stress. Cell. 2007;128:325-39.

10. Miyamoto K, Araki KY, Naka K, Arai F, et al. Foxo3a is essential for maintenance of the hematopoietic stem cell pool. Cell Stem Cell. 2007;1:101-12.

11. Zou P, Yoshihara H, Hosokawa K, Tai I, et al. p57(Kip2) and p27(Kip1) cooperate to maintain hematopoietic stem cell quiescence through interactions with Hsc70. Cell Stem Cell. 2011;2:247-61.

12. Matsumoto A, Takeishi S, Kanie T, Susaki E, et al. p57 is required for quiescence and maintenance of adult hematopoietic stem cells. Cell Stem Cell. 2011;2:262-71.

13. Yamazaki S, Iwama A, Takayanagi S, Morita Y, et al. Cytokine signals modulated via lipid rafts mimic niche signals and induce hibernation in hematopoietic stem cells. EMBO J. 2006;25:3515-23.

14. Yamazaki S, Iwama A, Takayanagi S, Eto K, et al. TGF-beta as a candidate bone marrow niche signal to induce hematopoietic stem cell hibernation. Blood. 2009;113:1250-6.

15. Karlsson G, Blank U, Moody JL, Ehinger M, et al. Smad4 is critical for self-renewal of hematopoietic stem cells. J Exp Med. 2007;204:467-74.

16. Rorby E, Hagerstrom MN, Blank U, Karlsson G, et al. Human hematopoietic stem/progenitor cells overexpressiong Smad4 exhibit impaired reconstitution potential in vivo. Blood. 2007;22:4343-51.

17. Yamazaki S, Ema H, Karlsson G, Yamaguchi T, et al. Nonmyelinating Schwann cells maintain hematopoietic stem cell hibernation in the bone marrow niche. Cell. 2011;23(147):1146-58.

18. Levéen P, Carlsén M, Makowska A, Oddsson S, et al. TGF-beta type II receptor-deficient thymocytes develop normally but demonstrate increased $\mathrm{CD} 8+$ proliferation in vivo. Blood. 2005; 106:4234-40.

19. Larsson J, Blank U, Klintman J, Magnusson M, et al. Quiescence of hematopoietic stem cells and maintenance of the stem cell pool is not dependent on TGF-beta signaling in vivo. Exp Hematol. 2005;33:592-6.

20. Oshima M, Oshima H, Taketo MM. TGF-beta receptor type II deficiency results in defects of yolk sac hematopoiesis and vasculogenesis. Dev Biol. 1996;10:297-302.

21. Alonzi T, Maritano D, Gorgoni B, Rizzuto G, et al. Essential role of STAT3 in the control of the acute-phase response as revealed by inducible gene inactivation [correction of activation] in the liver. Mol Cell Biol. 2001;21:1621-32.

22. Kawamoto T. Use of a new adhesive film for the preparation of multi-purpose fresh-frozen sections from hard tissues, wholeanimals, insects and plants. Arch Histol Cytol. 2003;66:123-43.

23. Mu D, Cambier S, Fjellbirkeland L, Baron JL, et al. The integrin alpha(v)beta8 mediates epithelial homeostasis through MT1MMP-dependent activation of TGF-beta1. J Cell Biol. 2002;157:493-507.

24. Chernousov MA, Carey DJ. AlphaVbeta8 integrin is a Schwann cell receptor for fibrin. Exp Cell Res. 2003;291:514-24.

25. Jessen KR, Mirsky R. The origin and development of glial cells in peripheral nerves. Nat Rev Neurosci. 2005;6:671-82.

26. Suzuki R, Arata S, Nakajo S, Ikenaka K, et al. Expression of the receptor for pituitary adenylate cyclase-activating polypeptide (PAC1-R) in reactive astrocytes. Brain Res Mol Brain Res. 2003;115:10-20.

27. Kiel MJ, Yilmaz OH, Iwashita T, Yilmaz OH, et al. SLAM family receptors distinguish hematopoietic stem and progenitor cells and reveal endothelial niches for stem cells. Cell. 2005;121:1109-21.

28. Nagasawa T. The chemokine CXCL12 and regulation of HSC and B lymphocyte development in the bone marrow niche. Adv Exp Med Biol. 2007;602:69-75.

29. Lai CY, Yamazaki S, Okabe M, Suzuki S, et al. Stage-specific roles for Cxcr4 signaling in murine hematopoietic stem/progenitor cells in the process of bone marrow repopulation. Stem Cells. 2014; 8.

30. Ding L, Saunders TL, Enikolopov G, Morrison SJ. Endothelial and perivascular cells maintain haematopoietic stem cells. Nature. 2012;48:457-62.

31. Yoshihara H, Arai F, Hosokawa K, Hagiwara T, et al. Thrombopoietin/MPL signaling regulates hematopoietic stem cell quiescence and interaction with the osteoblastic niche. Cell Stem Cell. 2007;13:685-97.

32. Ahdab R, Kikano R, Saade H, Riachi N. Early corticospinal tract Wallerian degeneration versus mesencephalic substantia nigra degeneration secondary to striatal stroke. Clin Neurol Neurosurg. 2014;118:101-2.

33. D'Antonio M, Droggiti A, Feltri ML, Roes J, et al. TGFbeta type II receptor signaling controls Schwann cell death and proliferation in developing nerves. J Neurosci. 2006;26:8417-27.

34. Noguchi E, Ohsawa H, Kobayashi S, Shimura M, et al. The effect of electro-acupuncture stimulation on the muscle blood flow of the hindlimb in anesthetized rats. J Auton Nerv Syst. 1999;75:78-86. 